\title{
A justiça e a democracia são incompatíveis?
}

PHILIPPE VONPARISS

$\sqrt{1}$ M UM PECULIAR vilarejo às margens do Volga, após uma longa seqüência de brindes para assinalar o fim de um curso de verão do qual eu havia participado, um homem de seus 60 anos - professor de filosofia na Academia de Ciências e membro ativo da Fundação Gorbatchov - aproximou-se de mim. "Você é belga", disse ele. (Ele não teria dito nada de muito diferente se eu fosse canadense ou suíço, ou mesmo espanhol). "Você sabe que para nós, habitantes da ex-URSS, a Bélgica representa algo importante. Ela constitui um raro exemplo de um Estado plurinacional bem-sucedido. $\mathrm{Na}$ Fundação Gorbatchov nós éramos, e continuamos sendo, muito ligados à Uniāo Soviética - não porque fosse soviética, mas sim porque era uma União. Acreditamos que somente uma União desse tipo pode garantir, não somente proteção efetiva às minorias existentes em suas diferentes regióes, mas também grau mais elevado de solidariedade entre suas regióes mais prósperas e mais pobres".

Ouvindo-o falar, senti um embaraço cada vez maior (e sem dúvida eu teria sentido a mesma coisa se fosse canadense), pensando nas mais recentes vicissitudes dos conflitos crônicos que caracterizam o Estado plurinacional que ele julgava ser tão bem-sucedido. Eu pensava, em particular, na recente exigência apresentada por várias organizaçóes culturais flamengas de sair do sistema de seguridade social do Estado belga. De forma vociferante, elas sustentam que cada um dos dois povos que constituem o Estado belga têm o direito de determinar todas as suas transferências interpessoais, cada qual segundo suas próprias preferências e de acordo com seus próprios recursos. Visando a esse objetivo, essas 'organizaçōes reivindicam insistentemente o fim do sistema existente, que transfere de Flandres (de língua holandesa, mais próspera e mais populosa) para a Valónia (de língua francesa, menos próspera e menos populosa) cerca de 3 a $4 \%$ de seus respectivos PIBs.

A conexão entre esses dois exemplos constitui um ponto de partida crucial para este artigo. Tanto a dissoluçăo da URSS quanto o possível rompimento do sistema de seguridade social belga impediriam a implementação de qualquer concepção de justiça que envolva uma forte solidariedade entre povos diferentes. $\mathbf{E}$ mais, nos dois casos isso se faz apelando-se, muito corretamente, a uma preocu- 
pação com a expansão da democracia. $O$ direito de um povo a determinar seu próprio destino, e de fazer à sua maneira suas próprias políticas sociais, está intimamente ligado, afinal, àquilo que se entende pelo ideal de democracia. Esses exemplos gêmeos motivam, assim, a tese que aqui tentarei demonstrar por meio de duas outras ilustrações: a de que a relação entre a democracia e a justiça, longe de exprimir a harmonia pré-estabelecida imaginada por boa parte da retórica política, em verdade é altamente problemática.

\section{Que justiça? Que democracia?}

Antes de prosseguir, preciso definir o que entendo por justiça e por democracia. Como adepto da navalha de Ockam e inveterado desbastador de conceitos flácidos, nos dois casos oferecerei uma definição deliberadamente simples - e mesmo simplista. Defino democracia como uma combinaçâo de regra da maioria, sufrágio universal e voto livre. É claro que cada um desses elementos requer mais esclarecimento. Mas, uma vez que meu argumento é em grande medida independente da especificação precisa de tais argumentos, não me deterei nisso, a não ser para enfatizar que minha definição de democracia leva em conta puramente procedimento. Uma sociedade é democrática porque suas decisões políticas são (fundamentalmente) tomadas segundo um procedimento que satisfaz às três condições mencionadas, e não porque essas decisões produzem um determinado resultado substantivo.

O segundo termo-chave, justiça, será aqui definido como a maximinização das condições materiais, possivelmente sujeita à satisfação de certas exigências tais como o respeito a liberdades fundamentais (1). O que torna uma sociedade justa, em outros termos, é o fato de que, graças às suas instituições, as condições materiais dos mais destituídos é (de forma duradoura) melhor do que seria se outras instituiçôes tivessem sido escolhidas.

Nessa caracterização de justiça, uso deliberadamente uma noção indeterminada de condiçôes materiais. Isso pode ser especificado em termos de renda, renda potencial, riqueza, padrão de vida, dotações, recursos, capacidades, benefícios sócio-econômicos etc. Para simplificar, aqui considero que a renda monetária líquida apresenta-se como um índice adequado dessas condiçóes materiais. Aplicado a essa variável, é o maximin que constitui o critério de justiça (2).

Argumento análogo ao que apresentarei a seguir aplicar-se-ia a fortiori a outras concepçóes de justiça. Um argumento similar aplicar-se-ia, por exemplo, a concepçóes de justiça mais igualitárias - isto é, a concepçóes que têm por implicação que uma deterioração nas condiçóes dos pior situados pode, se isso produzir maior igualdade de condições, levar a mais justiça. E também se aplicaria, ainda que mais fracamente, a concepçóes mais agregativas de justiça -, ou seja, a 
concepções que admitem que piora a nas condiçôes dos mais desafortunados pode, desde que isso leve à melhoria da situação média, conduzir a mais justiça. Assim, o maximin será utilizado aqui somente como um membro privilegiado de uma família maior de critérios distributivos aos quais o argumento se aplica.

Mesmo com todas essas precauções, a concepção de justiça aqui apresentada permanece específica e controversa. De uma parte, é uma concepção liberal de justiça no sentido de que ela não recorre, para decidir o que é justo, a nenhuma concepção específica da boa vida. Ao contrário disso, é uma concepção de justiça concebida de forma a ser compatível com o respeito igual às diferentes visões da boa vida que coexistem em nossas sociedades pluralistas. Dificilmente esta primeira restrição é um problema, à medida em que a grande maioria das concepçôes contemporâneas de justiça também são liberais nesse sentido.

Mas a concepção de justiça aqui proposta não é simplesmente liberal. É também solidária, no sentido de que requer uma atenção igual aos interesses de todos os cidadãos, uma consideração igual pelos interesses de todos os membros da sociedade. As concepçôes solidárias contrastam com as concepçóes de titularidade, que concebem a justiça somente como a ausência de qualquer violação de direitos naturais individuais preexistentes em todas as instituiçốes sociais (3).

A escolha de uma perspectiva solidária - e, em particular, do (critério) maximin de condições materiais aqui adotado como sua interpretação mais plausível - justifica-se pelo menos de duas formas. Em primeiro lugar, essa concepção de justiça é aquela com a qual estou (junto com Rawls, Sen, Dworkin e muitos outros) pessoalmente comprometido, de forma que ela naturalmente ocupará um lugar de destaque em minha reflexão sobre as relações entre justiça e democracia.

Além disso, é também intrinsecamente mais interessante explorar a relação entre democracia e justiça solidária do que a relação entre democracia e justiça enquanto titularidade. Para os que sustentam esta última concepção, a democracia constitui óbvia ameaça à justiça, entendida como o respeito a direitos individuais predefinidos. Os defensores da justiça como titularidade, por isso, concentram-se em estratégias institucionais que impõem limitações estritas ao exercício do poder democrático, por vezes chegando mesmo ao ponto de praticamente aniquilá-lo, para dessa forma garantir a proteção do indivíduo contra a opressão majoritária. Não é surpreendente, pois, que existam fortes tensôes entre a democracia c esse tipo de justiça, como já foi energicamente enfatizado por numerosos autores (4).

Mas quando a justiça é concebida como a consideração igual por todos os membros da sociedade, podemos naturalmente supor que, ao atribuir a cada um peso igual nos resultados dos procedimentos de votação, a democracia, tal como 
definida acima, é a aliada mais resoluta da justiça. Como veremos, esse não é o caso. A pressuposição de uma harmonia preestabelecida entre a justiça solidária e a democracia não resiste à análise (5).

\section{Maximed versus maximin}

Para entender uma primeira tensão entre democracia e justiça tal como aqui definidas, vamos partir de um modelo simples que incorpore as seguintes suposiçóes:

- a democracia opera por meio de um sistema eleitoral em que dois partidos se confrontam tentando cada qual obter uma maioria que the permita governar;

- os votantes:

- são motivados somente pelo seu interesse próprio individual, por sua vez determinado apenas pelo nível de renda de cada um,

- são perfeita e gratuitamente informados a respeito das implicaçóes dos programas dos dois partidos e, por isso,

- votam no partido cujo programa maximiza sua renda;

- a única questão a ser resolvida politicamente é a fixaçáo, entre 0 e $100 \%$, da taxa linear de gravação das rendas auferidas, imposto esse que será utilizado para financiar uma renda universal paga a todos;

- a renda total não é influenciada, nem mesmo após um intervalo de tempo, por esse nível de taxação.

Nesse modelo extremamente simplificado, para onde a dinâmica da democracia conduz? A resposta é clara: tudo depende dos níveis relativos da renda média e da renda mediana (6). O eleitor mediano é aquele cujo voto é necessário para a obtenção de $50+\mathrm{E} \%$ dos votos e cujas preferências são, em conseqüência, eleitoralmente decisivas. Se esse eleitor mediano ganha uma renda bruta maior do que a renda média, então qualquer taxação estritamente positiva o deixaria com uma renda líquida mais próxima à renda média, e por isso inferior a que ele receberia se a taxação fosse nula. Nesse caso, os dois partidos empenhados em obter o apoio eleitoralmente decisivo do eleitor mediano teriam interesse em propor $\mathbf{0 \%}$ de taxação e, portanto, uma distribuição de rendas líquidas idêntica à distribuição de rendas brutas. Se, em contraste, o eleitor mediano ganha uma renda bruta menor do que a renda média, então os dois partidos teriam interesse em propor uma taxação de $100 \%$ - e, portanto, uma distribuiçáo estritamente igualitária das rendas líquidas -, uma vez que em todos os casos de taxação inferior a essa o eleitor mediano receberia uma transferência líquida menor. Tanto em uma situação quanto na outra, é claro que a taxação de $100 \%$ é também aquela em que as rendas mais baixas são maximizadas. 
Uma característica universal da distribuição das rendas brutas nos países capitalistas é a de ser enviesada para cima. Conseqüentemente, a renda média encontra-se acima (e muitas vezes bastante acima) da renda mediana, o que faz da segunda das situaçōes mencionadas o caso pertinente. Assim, no contexto do modelo descrito, representado na figura 1 , não há tensão entre o que a justiça requer e para onde a democracia conduz. A maximização da renda mediana, garantida pelo processo democrático, coincide com a maximização da renda mínima, e isso é exatamente o que uma consideração igual pela condição de todos exige.

\section{Figura 1}

Rendas líquidas no caso das rendas brutas não serem afetadas pela taxação

\section{Renda \\ Líquida}

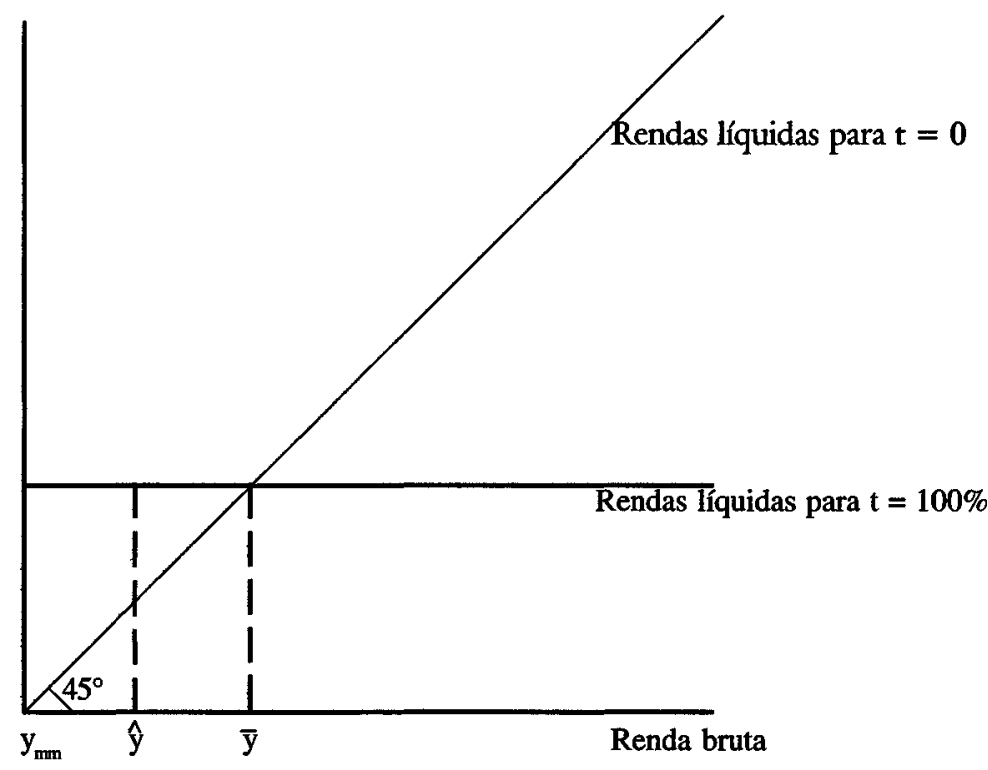

t = nível de taxação

$\hat{y}=$ renda bruta média

$\bar{y}=$ renda bruta mediana

$\mathrm{y}_{\mathrm{mm}}=$ renda bruta mais baixa

O modelo da figura 1, entretanto, apóia-se na suposição muito restritiva de que a renda total produzida em nada é afetada, nem mesmo a longo prazo, pela forma em que a renda é distribuída. Por exemplo, supóe-se que pagar a todos 
uma renda incondicional que absorva o total da renda disponível (mesmo que isso seja totalmente antecipado por todos os agentes econômicos) em nada diminuiria o entusiasmo por procurar emprego, empenhar-se no trabalho, poupar e fazer investimentos de risco, e também em nada diminuiria a capacidade das pessoas talentosas de exercerem seus talentos. Uma vez que se abandone essa suposiçáo altamente implausível, e que se leve em conta os efeitos dinâmicos dos impostos e transferências, rompe-se a harmonia entre a justiça e a democracia. É verdade que uma taxação de $100 \%$ ainda eleva tanto a renda mínima quanto a renda mediana para o nível da renda média. Mas a renda média (bruta ou líquida) com um imposto de $100 \%$ já não é igual ao que seria se não houvesse nenhum imposto. Muito possivelmente ela será consideravelmente menor - até mesmo menor do que seriam a renda mínima líquida $\mathrm{e}$ a renda mediana líquida se níveis mais baixos de taxação fossem adotados. Nesse caso, nem a preocupação de conquistar os favores do eleitor mediano, nem a preocupação de servir os interesses do mais destituído, nos levariam a defender uma taxaçâo de $100 \%$.

Além disso, e o que é mais importante para os nossos propósitos, não há razão para supor que essas duas preocupaçóes nos levariam a escolher o mesmo nível de taxação. A figura 2 mostra três curvas hipotéticas que representam a distribuição da renda líquida correspondente à taxações de $0 \%, 30 \%$ e $100 \%$, quando levamos em conta os efeitos dinâmicos ignorados na figura l. Vemos na figura 2 que, em comparação a uma taxação de $0 \%$, as taxações de $30 \%$ e de $100 \%$ levam, respectivamente, a uma renda média (e portanto total) ligeiramente mais baixa e consideravelmente mais baixa. Das três taxaçóes, entretanto, a melhor do ponto de vista do maximin ainda é a de $100 \%$ : ao passar de $30 \%$ para $100 \%$, o efeito positivo da igualização sobre a renda mínima mais do que compensa o efeito negativo, novamente sobre a renda mínima, proveniente da redução da renda agregada. Do ponto de vista da renda mediana, em contraste, o oposto é verdadeiro, e em consequiência a taxa preferida é a de $30 \%$.

A ordem de preferência correspondente aos dois pontos de vista, desse modo, deixam de coincidir, e não há mais qualquer razão para supor que o nível ótimo de taxação será o mesmo de acordo com os dois critérios. Na situação parcialmente descrita na figura 2, por exemplo, é bastante possível que a renda mediana seria maximizada com uma taxaçáo de $25 \%$, enquanto a renda mínima seria maximizada com uma taxação de $75 \%$. Com a introduçáo de suposiçóes mais realistas, a tranqüilizadora convergência entre o maximed da democracia e o maximin da justiça desapareceu inteiramente.

O modelo ainda permanece, é evidente, altamente implausível, mesmo depois de abandonar a suposição de que a renda agregada não é sensível a níveis de taxação. Os partidos podem ser muitos e seus programas multidimensionais; a taxação pode ser progressiva e as transferências fortemente diferenciadas; $o$ inte- 
resse pessoal dos eleitores pode não ser facilmente redutível em nível de sua renda líquida e (ou) a percepção que eles têm do impacto das diferentes plataformas partidárias sobre seu interesse pessoal pode ser altamente imprecisa e incerta. $O$ abandono dessas suposiçóes implausíveis (do modelo) tornaria as coisas consideravelmente mais complicadas. Entretanto, isso não ofereceria nenhuma esperança de abolir, nem mesmo de atenuar, a divergência entre a democracia e a justiça. Muito pelo contrário, a remoção de algumas das suposiçôes menos realistas aprofunda ainda mais o fosso entre o funcionamento efetivo de nossas democracias e a realizaçáo da justiça como maximin.

Figura 2

Rendas líquidas no caso de as rendas brutas serem negativamente afetadas pela taxação

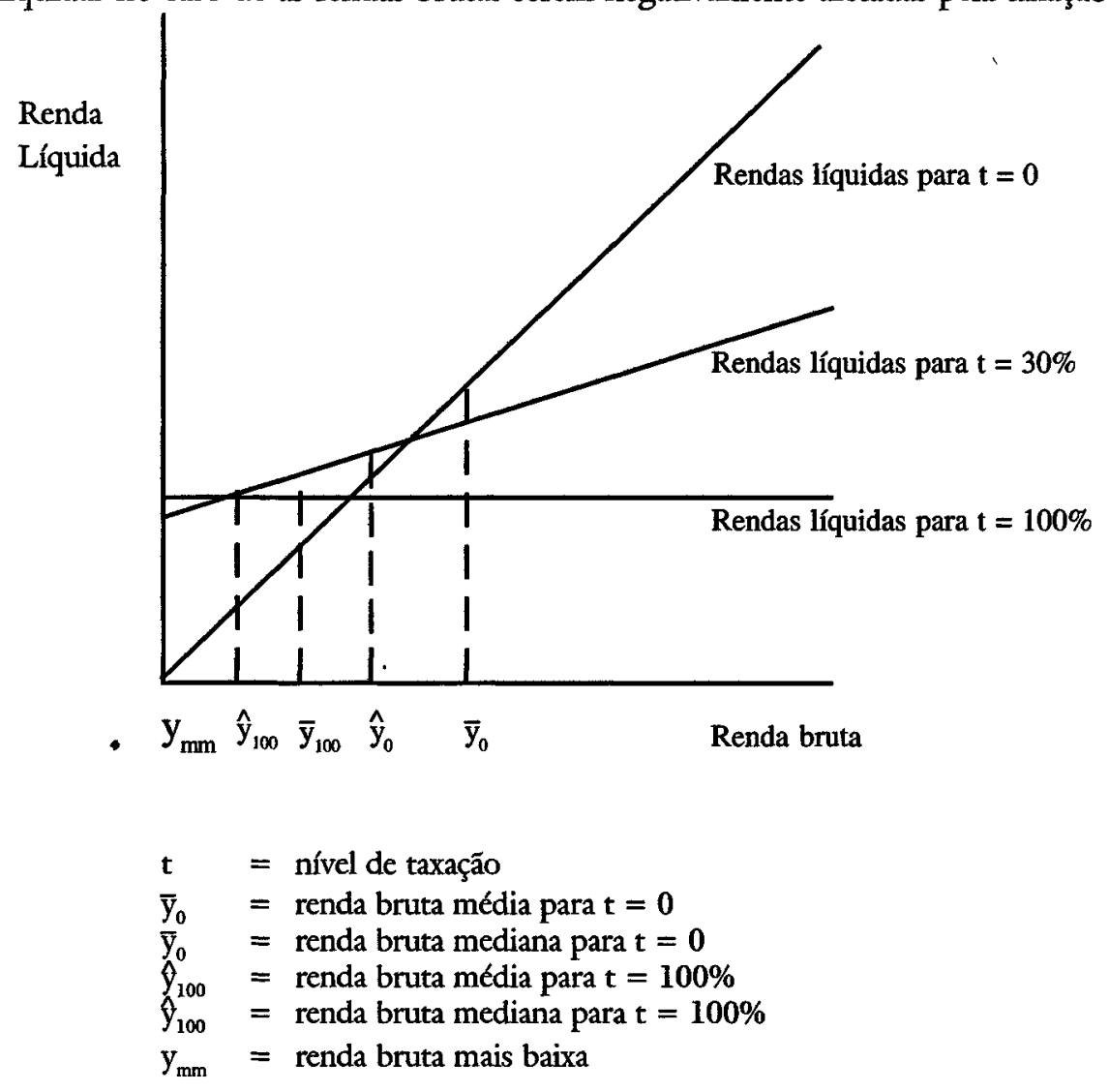

Para exemplificar, tenha em mente que é preciso tornar o partido e seus candidatos conhecidos dos eleitores; que o partido precisa convencer os eleitores de que sua plataforma eleitoral é, não somente mais próxima de seus (dos eleitores) interesses do que a de partidos adversários, e sim suficientemente próxima a ponto de valer a pena eles se darem o trabalho de ir votar; e que fazer isso tudo exige muito dinheiro. Se todos esses fatos forem devidamente levados em conta, 
torna-se ainda menos plausível nossa suposição de que a lógica da disputa democrática pelo voto das pessoas leva os partidos a defender políticas que maximizam a renda do eleitor mediano. Com certeza, um melhor prognóstico da plataforma eleitoral dos partidos é oferecido pela suposição rival da maximização da renda do dono do dólar mediano. E nesse caso, mesmo sem apelar para as consideraçóes dinâmicas discutidas anteriormente, vemos aprofundar-se o fosso entre o maximed da democracia e o maximin da justiça. Há realmente uma grande possibilidade de que o dólar mediano encontre-se no bolso de um eleitor cuja renda bruta é muito mais elevada do que a renda média. Entáo, mesmo excluindo-se (como na figura 1) todos os efeitos negativos da taxaçáo sobre a renda agregada, e mesmo persistindose nas demais suposições simplificadas já apresentadas, a dinâmica democrática conduz à escolha de uma taxação de $0 \%$ - que não poderia ser mais distante da taxação de $100 \%$ exigida, sob essas mesmas suposiçôes, pelo critério maximin de justiça (7).

Se nos desviamos do modelo inicial muito simplificado em qualquer uma dessas duas direções - introduzindo consideraçóes de dinâmica ou de poder econômico - a harmonia preestabelecida entre justiça e democracia obviamente desaparece. Em seu lugar surge uma profunda tensão, à qual voltarei logo adiante. Antes disso, entretanto, discutirei brevemente uma segunda tensão, bastante diferente da primeira.

\section{A democracia contra a migração}

Aplicando-se uma concepçãomaximin de justiça ao mundo como um todo, torna-se evidente que as disparidades de condição relacionadas a ser um cidadáo de um país e não de outro constituem vastas injustiças. Como essas injustiças podem ser reduzidas? A resposta óbvia é: eliminando-se as fronteiras internacionais. Isto é, a justiça exige que removamos os obstáculos à circulaçáo do capital (a seu movimento livre em direção aos países mais pobres, sobretudo) e à circulação de trabalhadores (a sua livre migraçáo para os países ricos, sobretudo). Mas é nessa direção que a democracia nos leva? Não é isso, com certeza, que uma rápida passada de olhos na evolução da problemática política das migrações de pessoas e de dinheiro ao longo do último século nos leva a pensar (8).

Quando as disparidades internacionais começaram a se ampliar devido à emergência da sociedade industrial, os países capitalistas estavam muito longe de ser democráticos. Politicamente, nem a entrada de trabalhadores estrangeiros, nem o êxodo de capital eram um problema naquele momento. Exercendo controle direto sobre o poder político, a burguesia tinha pouco a temer e muito a ganhar com o afluxo de mão-de-obra barata e ávida por trabalho (de pessoas com quem ela nem sequer corria o risco de ter que conviver em seus belos bairros). As fronteiras, consequientemente, podiam permanecer abertas. 
A exigência de obter um visto de entrada surgiu no curso do século XIX, mas somente após a Primeira Guerra Mundial tornou-se generalizada no mundo industrializado. $\mathrm{O}$ que provocou esse súbito fechamento geral das fronteiras, uma novidade na história da humanidade? Esse fato ocorreu essencialmente devido à conjunção de dois fatores: primeiro, o aprofundamento da desigualdade de condições em escala mundial, provocado pela expansão do capitalismo e pelo desenvolvimento demográfico e ecológico que, de forma mais ou menos direta, associaram-se a essa expansão; segundo, o crescimento do poder político da classe trabalhadora e de suas organizaçôes, intimamente relacionado à progressiva implementação do sufrágio universal. Em resumo, o fechamento das fronteiras foi o produto conjunto do capitalismo e da democracia. Enquanto o capitalismo gerava as pressóes migratórias, a democracia propiciava o poder de deter as migraçóes àqueles que com elas seriam prejudicados (em seus salários e ambiente de vida).

Se este esboço muito estilizado é pelo menos aproximadamente correto, então a própria extensão da democracia constitui um obstáculo à ampliação da justiça em escala mundial. Longe de haver uma harmonia preestabelecida entre justiça e democracia, também aqui é o próprio aprofundamento da democracia que cria um obstáculo cada vez mais robusto à realização em escala mundial da justiça como maximin das condiçóes. Ademais, a expansão da democracia a todos os países do mundo (o que, é evidente, não é o mesmo que o advento de uma democracia mundial) não enfraquecerá e sim, ao contrário, fortalecerá esse obstáculo (9).

Gavin Smith / AmeraPress

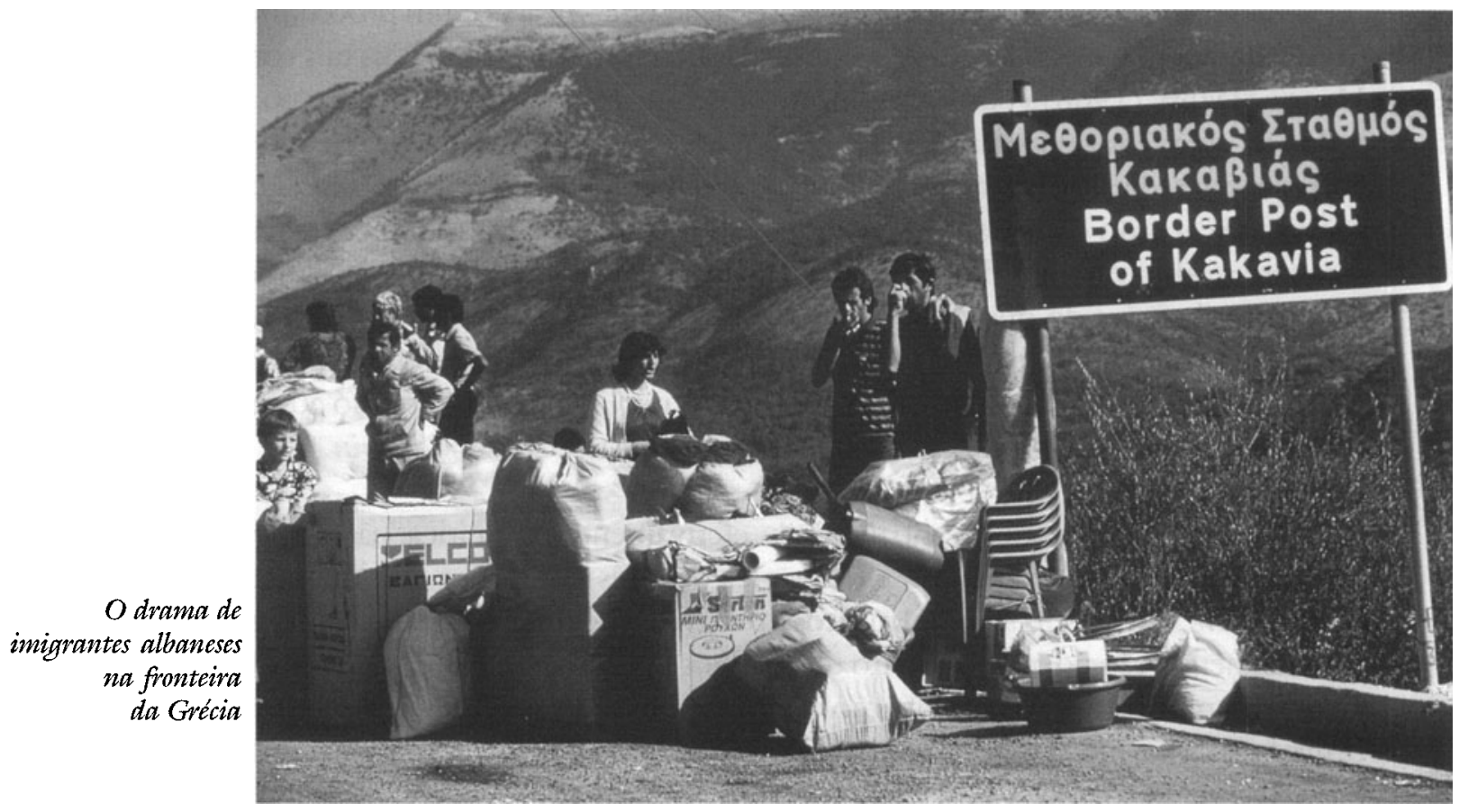




\section{Engenharia democrática}

Uma vez que estamos conscientes dessas duas tensóes muito distintas, a que conclusóes podemos chegar? Vou propor duas: uma delas, um tanto grosseira e, a outra, mais refinada.

Se não podemos supor uma harmonia preestabelecida entre justiça e democrácia - se, ao contrário, há razóes profundas para esperar conflitos agudos entre elas -, então temos que perguntar qual delas é preferível sacrificar. Minha resposta a essa questão é clara. Vamos aderir à justiça e sacrificar a democracia. Pois esta última não é um ideal importante por si mesmo. Ela constitui somente um instrumento institucional, do qual é legítimo se afastar se a busca do ideal assim o exigir (10). Enfatizo o se porque, se mais democracia pode nos levar para mais longe da justiça, menos democracia (nem é preciso dizê-lo) não necessariamente nos levará para mais perto dela (11).

Essa primeira conclusão é, sem dúvida, um pouco grosseira demais. Trata com excessiva brevidade o venerável tema da democracia. Mas, sobretudo, ela nem sequer enfrenta a questão que realmente importa, a saber, a de como escolher entre diferentes arranjos institucionais democráticos. Pois é difícil perceber como um procedimento não-democrático - que não satisfaça às três condiçóes mínimas apresentadas - poderia oferecer melhores garantias de realização da justiça, tal como aqui caracterizada.

No caso de outras concepções de justiça, a preferênçia por um procedimento não-democrático está longe de ser absurda. Economistas neoliberais tais como Henry Hazlitt (1968), por exemplo, propuseram retirar o direito de voto de todos os cidadãos que sejam devedores líquidos do Estado, com o objetivo de enfraquecer radicalmente as pressões eleitorais para aumentar as transferências sociais. De acordo com essa proposta, os beneficiários de transferências sociais somente readquiririam o direito de voto quando tivessem pago mais em impostos e contribuições do que recebido em benefícios (12). $\mathrm{O}$ fim do sufrágio universal, sem dúvida, reduziria a tensão entre a democracia e a justiça, tal como compreendida, esta última, por Hazlitt e outros neoliberais. Mas isso só aumentaria a distância entre o processo democrático e a justiça como maximin.

Para colocar a justiça comóm maximin efetivamente em prática, não é provável que tenhamos de renunciar a quaisquer das três condiçóes que definem a democracia. Ao contrário, é muito provável que respeitá-las com rigor (notadamente, estendendo o direito de voto aos imigrantes e eliminando os obstáculos administrativos à participaçáo eleitoral efetiva dos mais destituídos) constituiria condição indispensável a qualquer avanço nessa direção. A questão crucial, 
então, não é se a justiça requer a democracia no sentido mínimo adotado. O que importa saber é quais, entre os numerosos dispositivos de decisão coletiva que satisfazem as três condições mínimas, são mais suscetíveis de garantir a implementação da justiça tal como aqui concebida.

Para atenuar a primeira das duas tensões antes discutidas, por exemplo, é essencial que os mecanismos de decisão coletiva propiciem a eclosão de um debate público. Esse debate deve ser de molde a que todos os envolvidos possam fazer suas posições serem notadas e seus argumentos ouvidos; acima de tudo, ele deve ser de molde a que todos os envolvidos, somente pelo fato de se saber que eles ouvem, possam influenciar os conteúdos dos discursos e o teor das decisões. Unicamente a existência e a vivacidade de tal debate pode gerar e continuamente regenerar, no seio da sociedade, um senso de justiça que se conforma à concepção aqui adotada. Somente um debate como esse é suscetível de fazer da democracia um mecanismo institucional pelo qual torna-se possível, a esse senso de justiça, influenciar as leis que a sociedade se dá e, por meio dessas leis, $o$ funcionamento real da sociedade. Assim, não se trata apenas de que, institucionalizada dessa forma, a democracia constitua um meio promissor de realização de uma concepção solidária de justiça, tal como a maximinização das condições materiais. É também muito difícil encontrar-se outro fundamento mais plausível para a esperança de aproximar significativamente a forma como os recursos materiais, da justiça como maximin, são repartidos em nossas sociedades.

A tese geral que estou tentando formular, ilustrar e, por isso mesmo, sustentar, pode ser expressa da seguinte forma: na reflexão e na ação concernentes às instituições democráticas (nas quais se incluem o sistema eleitoral, o referendo, a descentralização, o equilíbrio dos poderes, o recrutamento, a remuneração e a alternância das autoridades eleitas, o financiamento das campanhas eleitorais $\mathrm{e}$ assim por diante), o que está em questão não são a elaboração e a busca de um ideal democrático que teria sentido por si mesmo. Não devemos, por exemplo, em nome da democracia enquanto um fim em si mesma, ter por objetivo instituir um sistema eleitoral que produza um legislativo que, estatisticamente falando, seja tão representativo quanto possível do povo. E tampouco devemos objetivar a organização de um sistema de tomada de decisões coletivas que seja tão próximo quanto possível da vontade popular, definida, por exemplo, como as preferências efetivas da maioria dos cidadãos.

A engenharia democrática pode ser vista como uma busca dos melhores trade-offs entre a independência e a submissão dos eleitos a sua base eleitoral; ou ainda a regra da maioria e as limitaçóes constitucionais; ou ainda entre a estabilidade política e a expressão da opinião da minoria. Nessa busca, entretanto, não devemos nos orientar por um ideal democrático autônomo (a igualdade de poder entre todos os cidadãos, a realização da vontade geral ou seja lá o que for). Em 
vez disso, devemos nos guiar por um ideal de justiça, com respeito ao qual qualquer ideal democrático que se possa formular constitui, no melhor dos casos, um instrumento e nada mais.

Pode ser útil esclarecer essa tese, e o contraste que a fundamenta, recorrendo a outro exemplo, bastante diverso dos até agora apresentados. Em 1931, ocorreu em Londres a segunda Round Table Conference para decidir o futuro político da Índia. Entre os participantes figurava B. R. Ambedkar, um advogado brilhante e líder político dos Intocápeis. Com o apoio dos britânicos, acordou-se que os Intocáveis escolheriam seus próprios representantes, e por isso não participariam das eleições gerais (13). Gandhi ficou tão escandalizado com essa decisão que começou uma greve de fome. Ambedkar cedeu e aceitou um compromisso, o Pacto de Poona, segundo o qual 148 cadeiras foram destinadas aos Intocáveis mas sem que o eleitorado fosse dividido. Em cada um dos distritos em questão, cujo número correspondia aproximadamente à proporção de Intocáveis na população total da Índia (cerca de 15\%), somente os candidatos da casta dos Intocáveis podiam concorrer - ainda que em cada um desses distritos constituíssem somente uma minoria da população. Nos outros distritos, as cadeiras seriam em princípio abertas aos membros de todas as castas, ainda que os Intocáveis fossem de fato praticamente excluídos delas (hoje ocupam três dessas cadeiras, de um total de mais de 400).

Mais de meio século depois, esse sistema introduzido pelo Pacto de Poona ainda está em funcionamento. E o fato de que tenha prevalecido sobre a proposta de Ambedkar provavelmente constitui um dos fatores cruciais para explicar a surpreendente estabilidade da democracia (formal) em um dos países mais populosos, vastos, pobres e divididos do mundo. Se um partido, no contexto do sistema efetivamente adotado, quer ter a possibilidade de conquistar as cadeiras reservadas aos Intocáveis, é forçado a recrutar candidatos entre as elites Intocáveis e, por isso, a ajustar seu programa eleitoral de acordo. É claro que esse sistema priva os mais radicais entre os Intocáveis de representação parlamentar, o que nos ajuda a compreender o desacordo passional entre Ambedkar e Gandhi. Mas, ao mesmo tempo, é provável que à sua vigência esteja ligado o fato surpreendente de que os Intocáveis desfrutem, já por quase meio século, de um notável leque de medidas de discriminação positiva. Por essa razão, não parece absurdo conjecturar que o sistema adotado contribuiu fortemente, não apenas para a estabilidade das instituições democráticas na Índia, mas também para a realização de uma concepção solidária de justiça naquele país (14).

A hipótese empírica mais geral que essa análise sugere é a seguinte: do ponto de vista da concepçáo de justiça com a qual estou comprometido, uma dinâmica democrática que inclua todas as categorias da população (tal como o sistema, retro descrito, vigente na Índia) é claramente preferível a uma dinâmica 
mista que combine a competição eleitoral dentro de cada categoria e a disputa de poder entre as diferentes categorias (o que teria ocorrido na India se Ambedkar tivesse levado a melhor) (15).

Esta hipótese pode ser verdadeira ou falsa. Mas para saber qual é o dispositivo democrático mais apropriado, é o tipo de hipótese que devemos formular. Não é antidemocrático privar a maioria (não-Intocavável) da elegibilidade nos distritos reservados aos Intocáveis? Sem dúvida. Mas o que importa é avaliar friamente, à luz das evidências empíricas e das análises teóricas, o impacto dos vários dispositivos institucionais possíveis no que diz respeito à realização da justiça social.

\section{Mundializar a democracia}

Essa perspectiva pode ser facilmente estendida para o duplo exemplo do qual parti. No caso da ex-União Soviética, como no caso da Bélgica (da Suíça, do Canadá ou da Espanha), a questão é saber se devemos permitir que os separatistas sigam seus caminhos separados, ou se devemos reter um nível federal de responsabilidade - e, neste caso, que poderes the devem ser atribuídos, que forma de representação política deve ser adotada nesse nível e assim por diante. Ao decidir tais questōes, nāo se deve perguntar pelo que é mais democrático. O que importa é identificar a distribuiçáo de competências e a forma de organizaçáo do poder que têm a melhor possibilidade de promover a realização, na máxima escala possível, da concepção de justiça com a qual estamos comprometidos.

Essa tarefa, nem é preciso dizer, é difícil e complexa, e rapidamente se desdobra em múltiplas subquestóes. Por isso, com respeito a esse duplo exemplo, não farei mais do que exprimir a conviç̧áo (talvez excessivamente) simples e (talvez excessivamente) forte que desenvolvi observando a situaçáo da Bélgica e da Europa. Do ponto de vista da concepçáo de justiça aqui adotada, é essencial que as decisōes mais importantes sobre a distribuição de recursos (e também sobre as liberdades fundamentais (16) devam ser:

- tomadas por um parlamento federal,

- cujos membros representem diretamente os cidadãos da federação e não as entidades federadas, $\mathrm{e}$

- no qual tudo o possível seria feito (no que se refere, por exemplo, ao método de votação, à constituiçăo de comissões parlamentares, às relaçóes com a mídia, e assim por diante) para garantir que as linhas decisórias determinantes sejam as ideológicas e não as nacionais (17).

O importante, em outras palavras, é que a dinâmica seja tal que as políticas adotadas năo constituam somente compromissos negociados entre os represen- 
tantes dos diversos grupos nacionais (18). Ao invés disso, essas políticas devem ser sujeitas à exigência de terem de justificar-se com base em argumentos que apelam aos cidadãos da federação como um todo (19).

Essa convicção ilustra, uma vez mais, a resposta que estou propondo para a questão levantada no título deste artigo. Se há uma compatibilidade entre a democracia e a justiça, isso não se deve a uma venturosa harmonia preestabelecida entre dois ideais. Essa compatibilidade só pode surgir como resultado de uma engenharia institucional laboriosa e engenhosa, por vezes abertamente maquiavélica. Essa engenharia institucional tem de visar, não somente ao estabelecimento e à preservação da democracia, mas, acima de tudo, à escolha daqueles dispositivos institucionais democráticos que, entre os inúmeros existentes, têm a probabilidade mais forte (ainda que de início muito frágil) de tornar nosso mundo um pouco mais justo, ou, pelo menos, um pouco menos imensamente injusto, do que é hoje.

Essa conclusão é particularmente verdadeira para a tensão mais pertinaz (ilustrada pelo exemplo da imigração), a saber, a que opte por uma democracia localizada em nível dos países (e ainda que fosse adotada por todos os países) à justiça solidária em âmbito mundial. Não é unanimemente incontroverso que esta seja realmente uma tensão com a qual deveríamos nos preocupar. Muitos argumentam que há uma diferença radical entre a justiça dentro de um país e a justiça em escala mundial; e que, se dentro de um país uma concepção solidária de justiça obviamente tem sentido, entre os países a justiça só faz exigências mínimas (tais como as normas de comércio internacional garantindo a equivalência dos bens trocados, a divisão equiitativa do excedente produzido pela cooperação mutuamente benéfica e a assistência residual no caso de fome ou catástrofes) (20). Ao contrário disso, o ponto de vista aqui adotado, quando aplicado ao exemplo duplo precedente e, sobretudo, quando estendido ao caso da migração, pressupóe que essa dicotomia é ilegítima: a concepção solidária pode ser legitimamente aplicada para além das fronteiras dos países; e se as instituiçốes democráticas que pudessem emprestar credibilidade a essa extensão ainda não existem, então se deveria lutar para que surgissem. As únicas fronteiras que são outra coisa que não uma pausa temporária imposta por imperativos pragmáticos no processo de globalização da democracia - em oposição à pura e simples difusão da democracia - e, por esse motivo, de globalização de uma concepção solidária de justiça, são as próprias fronteiras da humanidade (21).

A percepção dessa visão não implica drástica centralização, nem uniformidade em larga escala. Muito pelo contrário, desde que se faça uso sistemático do princípio da subsidiariedade, realização de uma concepção solidária de justiça e criação de instituições que a tornem possível, tais fronteiras são mais do que nunca necessárias para proteger a diversidade de culturas contra a uniformização 
acelerada que resulta do domínio crescente do mercado mundial. A visão solidária de justiça global não requer que se as coloque precipitadamente abaixo, permitindo-se assim que o fluxo migratório destrua as diferenças. Essa seria uma forma grosseira de contribuir para o maximin das condições em escala mundial. A necessidade de atacar as causas da mobilidade desempenhou um papel decisivo na pré-história do welfare state, na criação das instituiçóes que objetivavam garantir consideração igual por todos em escala nacional. Similarmente, da necessidade de estabilizar os errantes de nossa era - os migrantes transnacionais -, podemos esperar o impulso decisivo para o estabelecimento das instituições necessárias para realizar algo como uma consideração igual em escala mundial. Da mesma forma que no contexto nacional, essas instituições devem incluir um sistema de transferências individualizadas tão incondicionais e tão elevadas quanto possível.

Utópico? É claro que sim - e este é precisamente o tema central deste artigo -, uma vez que instituições democráticas apropriadas ainda não foram criadas (22). Mas não é o próprio estabelecimento de tais instituiçóes uma utopia? Já não é suficientemente ambicioso querer somente preservar, aprofundar e generalizar a democracia dentro de cada país? Uma democracia multinacional, se algum dia vier a existir, não está condenada a permanecer extremamente precária? (23) Talvez sim. E nesse caso a tensão entre justiça e democracia, ilustrada pelo exemplo da migração, permanecerá tão aguda como sempre. A justiça mundial e a democracia serão sempre incompatíveis.

Talvez não, pois todos nós, os povos da Terra, estamos nos tornando, muitas vezes pela dor e pelo conflito, mais conscientes de que compartilhamos da mesma superfície para nos movermos e habitarmos; de que direta ou indiretamente vivemos dos mesmos recursos naturais; de que nossos dejetos são lançados no mesmo ar e nas mesmas águas; de que nossos bens e serviços competem nos mesmos mercados; de que, em resumo, estamos condenados à interdependência cada vez mais estreita, da qual não resta outra escapatória a não ser levá-la adiante. E se a barbárie e o caos podem ser evitados, isso só é possível pela criação, não há dúvida que trabalhosa e meândrica, de verdadeiras instituiçôes democráticas para além do nível nacional.

Por essa razão, os fracassos e as dificuldades dos Estados supranacionais não deveriam nos desesperar. Em vez disso, esses fracassos e dificuldades devem nos educar e nos orientar. Em prol de meu interlocutor às margens do Volga, e de muitos outros pelo mundo afora, do que hoje necessitamos é tentar de outra maneira aquilo que antes não foi bem-sucedido e ousar tentar o que ainda não foi tentado. O que aqui está em questão é, no mínimo, reconciliação da democracia com a justiça. Mas talvez trate-se também de nossa própria sobrevivência. 
1 No que, em termos gerais, acompanho a linha de Rawls (1971).

2 Maximin refere-se ao princípio de justiça de Rawls, que propõe a máxima elevação da posição mínima (isto é, dos benefícios àqueles que se encontram na posição mínima) que seja compatível com o respeito aos direitos e liberdades civis e políticos (N.T.).

3 As diferentes famílias de concepçóes de justiça aqui sumariamente caracterizadas são formuladas e discutidas mais sistematicamente em Van Parijs (1991, cap.10).

4 O locus clássico é Hayek (1960, cap. 7), que menciona algumas das formulações anteriores dessa tensão entre democracia e liberalismo (como, por exemplo, as de José Ortega y Gasset, Hans Kelsen, entre outros).

5 Se julgamos que a definição de justiça solidária inclui a distribuição igual a todos do direito de voto e da liberdade de expressão - como é o caso em Rawls (1971; 1993) -, então é evidente que essa tensão simplesmente se dissolve: uma sociedade não-democrática é necessariamente injusta. Ou melhor, a tensão precisa ser reformulada como uma tensão interna entre os diferentes componentes da justiça como consideraçäo igual.

6 Esta seção inspira-se, é claro, na (versão mais elementar da) teoria econômica da democracia, cujas origens remontam a Downs (1957). Ver, por exemplo, Ordeshook (1986) para uma revisão da literatura.

7 Entre outras complicaçóes que valeria a pena explorar, encontra-se a lacuna entre o impacto efetivo e o impacto esperado dos vários programas eleitorais. Se os eleitores são tipicamente vítimas de uma ilusão estática, que os leva a negligenciar o impacto dinâmico das redistribuições que estão sendo examinadas, não teria o eleitor mediano uma tendência a promover, acreditando que isso serviria melhor seu interesse pessoal, uma política redistributiva que serviria ainda muito mais aos interesses dos eleitores mais pobres do que ele? É possível. Mas, ao invés disso, a tendência hoje - como resultado do colapso espetacular do comunismo europeu sobretudo, mas também devido à incerteza provocada por uma imersão cada vez mais profunda no mercado mundial - não é a do eleitorado superestimar as conseqüências negativas de políticas fortemente solidaristas?

8 Esta seção inspira-se em várias das contribuiçóes que aparecem na estimulante coletânea organizada por Barry \& Goodin (1992).

9 Desse modo, enquanto deve-se atribuir o fechamento das fronteiras ao capitalismo e à democracia conjuntamente, é a democracia, e não o capitalismo, que aqui encontra-se em conflito com a justiça como maximin. É claro que é o capitalismo que gera um desenvolvimento muito desigual; mas é a democracia que bloqueia a difusão mais ampla dos frutos desse desenvolvimento por meio da migração. Para a elaboração menos sumária dessa análise muito esquemática das relações entre capitalismo, migração e justiça global, ver Van Parijs (1993, cap.7).

10 Essa visão puramente instrumental de democracia, bem entendido, está longe de ser nova. Schumpeter (1943:242), por exemplo, observa que "a democracia é um método político ... incapaz de se constituir em um fim em si mesmo, independentemente de que decisóes ela produzirá em determinadas circunstâncias históricas. E este precisa ser o ponto de partida de qualquer tentativa de defini-la". Hayek $(1960: 106,117)$, de forma similar, sustenta que "por mais forte que seja o argumento geral em favor da democracia, ela não é um valor último ou absoluto e deve ser julgada pelo que realiza. Provavelmente, trata-se do melhor método para realizar determinados fins, mas não é um fim em si mesmo ... O perigo é o de confundir um meio de assegurar a justiça com a própria justiça". Essas concepçôes encontram-se mais desenvolvidas em Dworkin (1989), que distingue as concepçóes independentes de democracia (que 
a justificam sem qualquer referência a suas conseqüências) das concepçóes dependentes (que propõem uma justificação conseqüiencialista das instituiçōes democráticas). É claro que a justiça, mesmo diferentemente interpretada, constitui somente um dos fins por referência aos quais essas concepções dependentes (i.e., instrumentais) definem-se. A paz e o crescimento, por exemplo, são outras possibilidades. Mas para Dworkin, assim como para Hayek, a democracia justifica-se também por ser instrumental à justiça.

11 É por isso que às vezes pode ser politicamente oportuno denunciar reformas indesejáveis repudiando sua natureza antidemocrática, mesmo que não seja esse o real fundamento de por que elas são indesejáveis (Norman, 1990:119).

12 Hazlitt, 1968. A mesma idéia encontra-se na observação de Hayek (1960:105) de que "também é possível ... que os ideais de democracia seriam melhor servidos se, digamos, todos os funcionários públicos ou todos os beneficiários da caridade pública fossem excluídos do direito de voto".

13 Uma solução desse tipo está hoje em vigor na Nova Zelândia com respeito às quatro cadeiras reservadas aos Maoris, que também encontram-se geograficamente dispersos (Nagel, 1993:11).

14 Para mais detalhes e nuanças, ver Deliège (1993) e Jaffrelot (1993).

15 Nos Estados Unidos, adotou-se o gerrymandering - a redefinição ad hoc dos distritos eleitorais - para tentar assegurar, a despeito do sistema majoritário uninominal, uma representação significativa às minorias dispersas (sobretudo aos negros). Mas do ponto de vista de uma concepção solidária de justiça, esta solução é pouco atrativa - e não há dúvida de que ela contribuiu notavelmente para o desempenho pífio do país mais rico do mundo em matéria de política social. Como nota Douglas Rae (1993), a solução tem como subproduto inevitável o de maximizar o número de membros do Congresso que praticamente não tem negros em seus eleitorados: "ela libera a maioria dos representantes de qualquer ansiedade com respeito às necessidades $\mathrm{e}$ às percepçóes dos afro-americanos. Certamente, não é disso que necessitamos para assegurar resultados melhores e mais equiitativos em escala nacional".

16 Como foi notado no início, a maximinização das condições pode ser sujeita à exigência de um respeito estrito pelas liberdades fundamentais. E uma tarefa central da engenharia democrática - na escolha, por exemplo, entre a democracia monista, a democracia dualista e a democracia pluralista (Ackerman, 1991) - conseqüentemente consistirá na determinação do status e do conteúdo ótimos das garantias constitucionais. A hipótese aqui delineada, no que diz respeito a este componente de uma concepção completa de justiça social, é a de que a probabilidade de uma entidade mais abrangente definir de forma adequada (pelos padróes dessa concepção de justiça) as liberdades fundamentais, e de protegê-las efetivamente, é maior do que a de que entidades menores, e por isso mesmo provavelmente mais homogêneas etnica, lingüistica e culturalmente, o façam.

$17 \mathrm{Na}$ mesma linha, o exemplo hindu discutido na seçáo anterior sugere que se um dia a Comunidade Européia tiver de escolher seu presidente por voto direto, pode ser aconselhável impor a cada vez (e por rodízio) o(s) Estado(s) do(s) qual(quais) os candidatos devem ser cidadãos, eleições essas, bem entendido, em que todos os cidadãos europeus teriam o direito de voto.

18 À maneira do Conselho de Ministros da Comunidade Européia, da conferência dos presidentes da Confederação dos Estados Independentes ou do diálogo de comunidade a comunidade que às vezes ameaça de curto-circuito o parlamento da Bélgica.

19 A importância dessa distinção entre argumentar e negociar é proveitosamente enfatizada por Elster (1991) no contexto de uma análise comparativa de Assembléias Constituintes. 
20 Algumas variantes dessa visão encontram-se no documento de organizações flamengas, já mencionado, e também na formulação que Rawls (1993b) recentemente deu à extensão de sua concepção de justiça como eqüidade ao direito das gentes.

21 Estou aqui tomando partido incondicionalmente daqueles rawlsianos que estão resistindo às idéias do próprio Rawls sobre como sua perspectiva aplica-se à justiça global. Ver, por exemplo, Pogge (1994) e, mais energicamente, Barry (1994).

22 Por meio dos sistemas de transferências individuais produzidos pelo funcionamento de instituições democráticas no nível do Estado belga, Flandres (5.800.000 habitantes) transfere anualmente (em termos líquidos) à Valônia (3.300.000 habitantes) perto de $3 \%$ de seu PIB, o que equivale a cerca de 3 bilhóes de dólares ou a 2,5 vezes o PIB de um país como Burundi (5.600.000 habitantes). Comparando-se esse montante às somas derrisórias que a Bélgica transfere anualmente ao Burundi (um de seus antigos protetorados) à guisa de cooperação ao desenvolvimento, podemos ter uma idéia da diferença que faz pertencer à mesma entidade democrática. Um exemplo intermediário é oferecido pelas transferências líquidas ao Estado membro da Comunidade Européia que mais se beneficia do conjunto de sistemas de transferências sociais comunitárias (os fundos estruturais): Portugal (com 10.600.000 habitantes e um PIB per capita de menos da metade daquele da Valônia) recebe anualmente cerca de US\$ 1 bilhão em transferências líquidas do restante da Comunidade Européia. (As principais fontes dessas cifras são L'Etat du monde (Paris, La Découverte, 1992) e Le Feder en chiffres 19751988 (Luxemburgo, Fonds Européen de Développement Régional, 1988).

23 Como acreditava John Stuart Mill (1861:291-292).

\section{Referências bibliográficas}

ACKERMAN, B.A. We, the people: foundations. Cambridge, Harvard University Press, 1991.

BARRY, B. Theories of justice. Hemel-Hempstead, Harvester-Wheatsheaf, 1989.

- Dirty work at the original position. Paper apresentado na Conferência The ethics of nationalism, Universidade de Illinois, abril 1994.

BARRY, B. \& R.E. Goodin (orgs.). Free movement: ethical issues in the transmational migration of people and of money. Hemel-Hempstead: Harverster-Wheatsheaf, 1992.

DELIÈGE, R. Le système des castes. Paris, PUF, 1993.

DOWNS, A. An economic theory of democracy. New York, Harper, 1957.

DWORKIN, R. What is equality? (Part IV: Political equality). University of San Francisco, Law Review, n. 22, p. 1-30, 1983.

ELSTER, J. Arguing and bargaining in two Constituent Assemblies. The storrs lectures. New Haven, Yale Law School, 1991 [mimeo].

HAYEK, F.A. The constitution of liberty. Londres, Routledge \& Kegan Paul, 1960.

HAZLITT, H. Income without work. In: Bunzel, J.H. (org.). Issues of American public policy. Englewood Cliffs, Prentice-Hall, 1968.

JAFFRELOT, C. La démocratie Indienne entre archaisme et modernite. Paris, Fondation Saint Simon, 1993. 
MILL, J.S. Considerations on representative government. Oxford, Blackwell, 1861.

NAGEL, J. Lessons of the impending electoral reform in New Zeland. PEGS Nemsletter, v. 3, n. 1, p. 9-10, 1993.

NORMAN, W. Démocratie juste ou justice démocratique? Universidade de Caen, Cabiers de Philosophie Politique et Juridique, n. 18, p. 109-124, 1990.

ORDESHOOK, P.C. Game theory and political theory: an introduction. Cambridge, Cambridge University Press, 1986.

POGGE, T. An egalitarian law of peoples. Philosophy and Public Affairs, n. 23, 1994.

RAE, D.W. Proportional representation over gerrymandering. PEGS Nesletter, v. 3, n. 1, p. 1314, 1993.

RAWLS, J. A theory of justice. Oxford, Oxford University Press, 1971.

Political liberalism. New York, Columbia University Press, 1993a.

. The law of peoples. Critical Inquiry, n. 20, p. 36-68, $1993 \mathrm{~b}$.

SCHUMPETER, J. Capitalism, socialism and democracy. Londres, Allen \& Unwin, 1943.

VAN PARIJS, P. Qu'est-ce qu'une société juste? Introduction à la pratique de la philosophie politique. Paris, Le Seuil, 1991.

Marxism recycled. Cambridge, Cambridge University Press, 1993.

\section{Resumo}

Ao contrário do que muitas vezes se supõe, não há nenhuma harmonia preestabelecida entre a democracia e a justiça. $\mathrm{O}$ autor examina um exemplo teórico e exemplos empíricos, mostrando que a lógica e o funcionamento da primeira podem entrar em choque com as exigências da segunda. Ao contrário da justiça, argumenta o autor, a democracia não é um valor em si mesmo. Se queremos harmonizá-las, a questão realmente importante é avaliar quais, entre ós diferentes dispositivos institucionais democráticos, são mais favoráveis à realizaçáo da justiça.

\section{Abstract}

Contrary to a widely held conviction, there is no pre-established harmony between democracy and justice. Theoretical and empirical illustrations are provided in order to highlight the ways in which democracy may clash with justice. It is argued that the former, in contrast to the latter, is not to be viewed as a value in itself. If we wish to harmonize them, the important question to ask is which among the numerous democratic setups is the most capable of ensuring the implementation of justice.

Pilippe Van Parijs, economista, é professor da Universidade Católica de Louvain, na Bélgica. No dia 2 de agosto de 1994 ele apresentou sua proposta de capitalismo de renda básica em seminário organizado no IEA. 
Este artigo se baseia também em conferências apresentadas pelo autor na Universidade Livre de Bruxelas (25/2/1992), no Seminário Democracia e Comunicação do CNRS (Paris, 24/4/1992), na Sociedade Filosófica de Montreal (31/3/1993), na Universidade de Laval (Québec, 1/4/1993), na Universidade de Lausanne (13/5/1993), na Universidade Autônoma de Barcelona (17/6/1993) e no Centro de Estudos de Cultura Contemporânea (Sáo Paulo, 29/7/1994).

Tradução de Álvaro de Vita. O original em inglês - La justice et la démocratie sont-elles incompatibles? - encontra-se à disposição do leitor no IEA-USP para eventual consulta. 